Check for updates

The BMJ

Cite this as: BMJ2020;371:m3967 http://dx.doi.org/10.1136/bmj.m3967 Published: 13 October 2020

\section{Covid-19: Johnson and Johnson vaccine trial is paused because of unexplained illness in participant}

Elisabeth Mahase

Pharmaceutical company Johnson and Johnson has temporarily paused dosing in all its covid-19 vaccine trials while an investigation is carried out into an unexplained illness in a study participant. ${ }^{1}$

The adverse event is being reviewed by an independent data safety monitoring board as well as the company's internal clinical and safety physicians. No further details have been provided about the illness or the health of the participant.

“We must respect this participant's privacy. We're also learning more about this participant's illness, and it's important to have all the facts before we share additional information," Johnson and Johnson said in a statement.

The vaccine candidate reached phase III testing in September, when the multi-country Ensemble trial was launched. Ensemble is a randomised, double blind, placebo controlled study designed to determine whether the vaccine is safe and effective in adults aged between 18 and 60 as well as those over 6o years old.

The company hopes to recruit 60 ooo people, 30 ooo of whom will be given a single dose of the vaccine, in countries such as Argentina, Brazil, Chile, Colombia, Mexico, Peru, South Africa, and the US. The trial includes participants with and without comorbidities associated with an increased risk of severe covid-19.

Johnson and Johnson also has an agreement with the UK to run a separate phase III trial in multiple countries which will investigate a two dose regimen. ${ }^{2}$

The vaccine candidate uses the Adenovirus 26 vector-the same technology used to develop the company's Ebola vaccine and its HIV, respiratory syncytial virus, and Zika vaccine candidates-combined with the SARS-CoV-2 spike protein.

In its statement, the drug company said that all of its clinical studies have prespecified guidelines to ensure that they are paused if an "unexpected serious adverse event that might be related to a vaccine or study drug is reported, so there can be a careful review of all the medical information before deciding whether to restart the study."

This comes after the University of Oxford and AstraZeneca covid-19 vaccine candidate trial was paused in September for the second time, following a severe adverse event. ${ }^{3}$ The trial has since resumed in multiple countries except for the US, where the Food and Drug Administration is continuing to investigate the incident. ${ }^{4}$

1 Johnson \& Johnson temporarily pauses all dosing in our Janssen covid-19 vaccine candidate clinical trials. 12 October 2020. www.jnj.com/our-company/johnsonjohnson-temporarily-pauses-all-dosing-in-our-janssen-covid-19-vaccine-candidate-clinical-trials.

2 Johnson \& Johnson announces collaboration in principle with the United Kingdom on additional phase III study and agreement to supply its covid-19 vaccine candidate. 14 August 2020. www.jnj.com/our-company/johnson-johnson-announces-collaboration-in-principle-with-the-united-kingdom-on-additional-phase3-study-and-agreement-to-supply-its-covid-19-vaccine-candidate.

3 Mahase E. Covid-19: Oxford researchers halt vaccine trial while adverse reaction is investigated. BMJ2020;370:m3525. doi: 10.1136/bmj.m3525 pmid: 32907856

4 Exclusive: FDA widens US safety inquiry into AstraZeneca coronavirus vaccine. Reuters. https://uk.reuters.com/article/health-coronavirus-vaccine-astrazeneca/exclusive-fda-widens-us-safety-inquiry-into-astrazeneca-coronavirus-vaccine-sources-idUKL1N2GR1SK. 